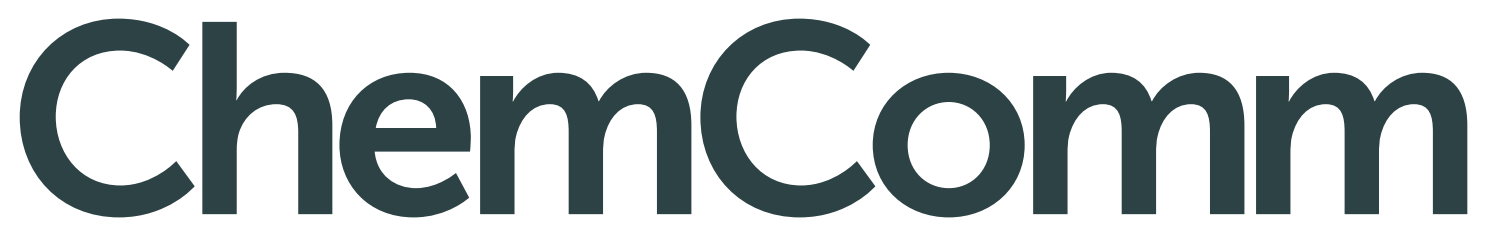

Chemical Communications www.rsc.org/chemcomm

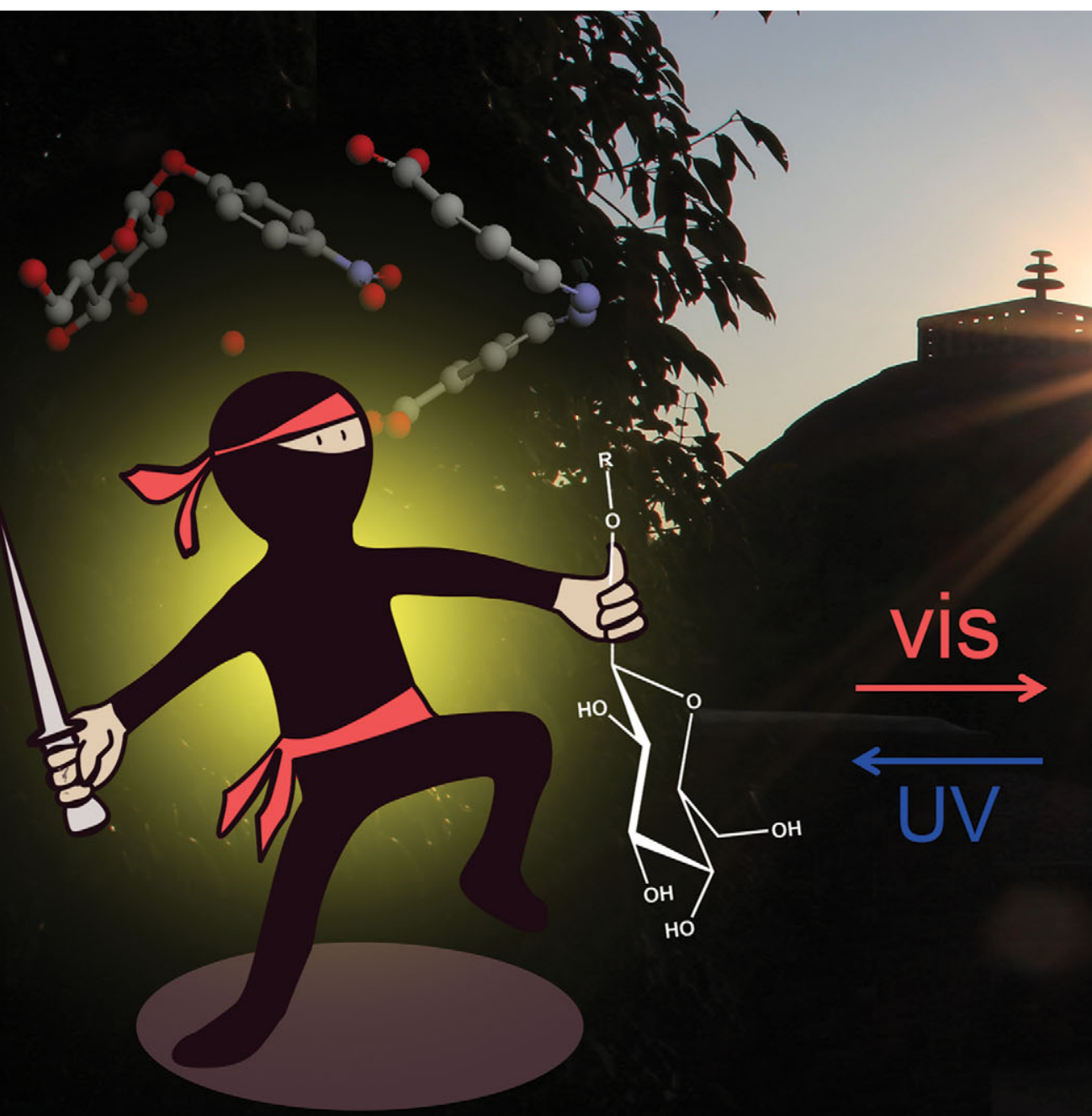

Glycosidase mimic

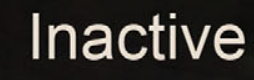




\title{
ChemComm
}

\section{A photoresponsive glycosidase mimic $\uparrow$}

\author{
Cite this: Chem. Commun., 2014 \\ 50, 10577 \\ Received 6th May 2014, \\ Accepted 4th June 2014
}

Mousumi Samanta, V. Siva Rama Krishna and Subhajit Bandyopadhyay*

DOI: $10.1039 / c 4 c c 03394 a$

www.rsc.org/chemcomm

\begin{abstract}
Azobenzene-3,3' -dicarboxylic acid exists in photoisomerizable $(E)$ and (Z)-forms. Deprotonation of the carboxylic acid groups from the $(E)$-form occurs simultaneously, whereas in the (Z)-form it occurs in a stepwise fashion. The mono anionic form of the $(Z)$-isomer acts as a glycosidase mimic that proceeds through a general acid-general base catalytic mechanism. This is the first example of a photoresponsive glycosidase mimic.
\end{abstract}

Biological functions can be regulated by $\mathrm{pH}$, ions or signalling molecules. Certain biological events can be regulated by light stimuli. The most common instance of the regulation of a protein function by light is the photoisomerization of retinal in rhodopsin. Photoisomerization of synthetic photoswitches and subsequent optical control of biological functions are cutting edge areas of research in Chemistry and Chemical Biology. ${ }^{1-5}$

Although a large number of photochromic systems are available, chemists have frequently made use of the azobenzene photochrome because of its convenient synthesis, well established $(E)-(Z)$ photoisomerization and more importantly, a large change in the molecular geometry upon irradiation with UV and visible light and constructed a host of molecular devices. ${ }^{6}$ Binding of cations, ${ }^{7}$ anions $^{8}$ and molecules ${ }^{9}$ has also been investigated using receptor linked azobenzene systems. Thus, it is conceivable that with proper substitution on the azobenzene molecule, the photochromic switch can bind to other small molecules having complementary substitution patterns through H-bonding and other non-covalent interactions.

It was thought that $(E)-(Z)$ isomerization of azobenzene-3,3'dicarboxylic acid might lead to the modulation of $\mathrm{p} K_{\mathrm{a}}$ values of the two acid groups. Consequently, this may alter the catalytic activities in the two forms of the photoswitchable system.

Photomodulation of acidity in a diarylethene (DAE) compound bearing a phenol and a pyridinium group at the two

Department of Chemical Sciences, Indian Institute of Science Education and Research (IISER) Kolkata, Mohanpur, WB 741246, India. E-mail: sb1@iiserkol.ac.in $\dagger$ Dedicated to Prof. H. Ila on the occasion of her 70th birthday.

\$ Electronic supplementary information (ESI) available. See DOI: 10.1039/ c4cc03394a ends of the molecule has been demonstrated. ${ }^{10}$ Photomodulation of $\mathrm{p} K_{\mathrm{a}}$ in the DAE systems has also been studied. ${ }^{11,12}$ Detailed quantitative studies on photomodulation of $\mathrm{p} K_{\mathrm{a}}$ of a DAE based diacid have recently been conducted by Coudret, Delbaere and coworkers. ${ }^{13}$

There are examples of reversible modulation of basicity ${ }^{14 b}$ and catalytic activity by light. ${ }^{14}$

Glycosidases are a class of enzyme that catalyses the hydrolysis of glycosidic bonds. The mechanism for the glycoside hydrolysis involves general acid-base catalysis (Fig. 3A). ${ }^{20,21}$ Taking inspiration from nature, chemists have demonstrated that synthetic molecules can perform similar functions to that of the natural systems for which Breslow has coined the term biomimetic chemistry. ${ }^{15}$ To mimic the glycosidic process with enzyme-models, ${ }^{16}$ Bruice, ${ }^{17 a}$ Fife $^{17 b}$ and Kirby ${ }^{17 c}$ have worked on intramolecular enzyme models. Bols $^{18}$ and Striegle ${ }^{19}$ have recently contributed immensely to the field of supramolecular glycosidase mimics. A per-O-methylated cyclodextrin based diacid has been used by Bols and co-workers to catalyze the glycosidic bond cleavage with appreciable rate enhancement. ${ }^{18 e}$ However, to date there has not been any report on the regulation of the glycosidase activity of enzyme mimics with light. Here we report the photomodulation of $\mathrm{p} K_{\mathrm{a}}$ of a photochromic azobenzene dicarboxylic acid and demonstrated the activity of its acid-conjugate base form as a glycosidase mimic.

Azobenzene-3,3'-dicarboxylic acid exists in two forms, $(Z)$ and $(E)$ (Fig. 1). The $(E)$ form upon exposure to UV light $(366 \mathrm{~nm})$ converts into the $(Z)$ form with a photostationary state having $c a .70 \%$ of the $(Z)$ isomer (Fig. S1, ESI ). The $(Z)$ form quantitatively reverts to the $(E)$ form with visible light and heat.

For the determination of the $\mathrm{p} K_{\mathrm{a}}$ values of the $(E)$-acid, the $\mathrm{pH}$ titration was studied by UV-vis spectroscopy. The sigmoidal titration curve thus obtained from the absorbance values against the $\mathrm{pH}$ is shown in Fig. 2B. From the plot, a single $\mathrm{p} K_{\mathrm{a}}$ value for the $(E)$ form of azobenzene was obtained at $\mathrm{pH} 4.4$ $( \pm 0.1)$.

To convert it to the (Z)-form, a sample of the $(E)$-dicarboxylic acid was irradiated at a wavelength of $366 \mathrm{~nm}$ and $0{ }^{\circ} \mathrm{C}$ for 2 hours and the $\mathrm{p} K_{\mathrm{a}} \mathrm{s}$ were determined from the absorbance 


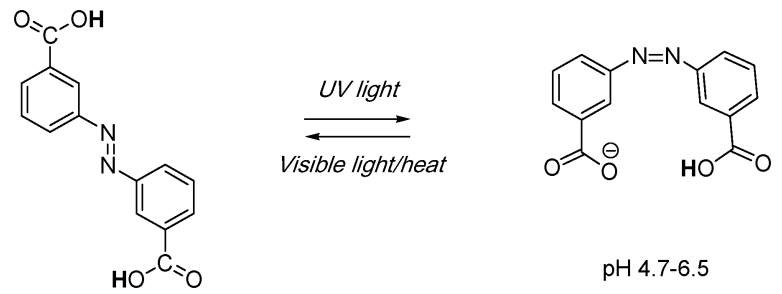

Fig. 1 Photomodulation of $p K_{a}$ in an azobenzene photoswitch.
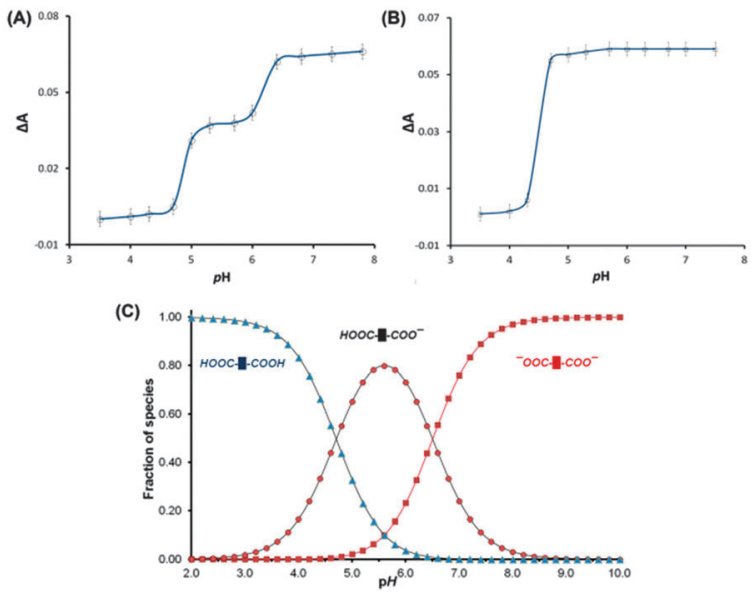

Fig. $2 \mathrm{pH}$ titration curve (A) for (Z)-1 and (B) for (E)-1. (C) The species distribution diagram as a function of $\mathrm{pH}$ for $(Z)-\mathbf{1}$.

values at different $\mathrm{pH}$. A double sigmoidal plot obtained in this case revealed the two distinct $\mathrm{p} K_{\mathrm{a}}$ values of $4.7( \pm 0.1)$ and 6.5 $( \pm 0.2)$ (Fig. 2A). Thus the deprotonation of the two carboxylic groups of the $(Z)$-acid took place in a stepwise fashion and the molecule exists in an acid-conjugate base $\left(\mathrm{COOH}-\mathrm{COO}^{-}\right)$form between $\mathrm{pH} 4.7$ and 6.5. This species is akin to the active form of a glycosidase in terms of functionality. Following the natural glycosidase model of a general acid-general base catalysis, ${ }^{20}$ the $(Z)$ isomer in the mono-protonated form was studied as a glycosidase mimic using 4-nitrophenyl- $\beta$-D-glucopyranoside as the model substrate. The hydrolyzed product has an intense characteristic absorption at $400 \mathrm{~nm}$. The generation of the phenolic species (Fig. 3B) from the depletion of the glycopyranoside was monitored with UV-visible absorption to study the catalytic activity (for details $c f$. ESI $\ddagger$ ).

The pH-rate profile of the hydrolysis using the $(Z)$-isomer displayed a bell shaped curve (Fig. 4A) with a maximum at $\mathrm{pH}$ around 5.8. These results correlate well with the species distribution diagram where it is observed that the population of the active acidconjugate base form of the $(Z)$ dicarboxylic acid is maximum within the same $\mathrm{pH}$ range (Fig. 2C). The bell-shaped $\mathrm{pH}$-rate profile indicates a typical characteristic feature of a general acid-base catalysis for the glycosidic bond cleavage reaction. Similarly, the pH-rate profile of the hydrolysis by the $(E)$ azobenzene derivative was also monitored (Fig. 4B). The data points were fitted to a sigmoidal graph indicating that the reaction is general base catalyzed. It should be noted that the glycosidase mechanism may vary depending on the natural glycosidase ${ }^{20}$ or the enzyme model. ${ }^{21}$
A.

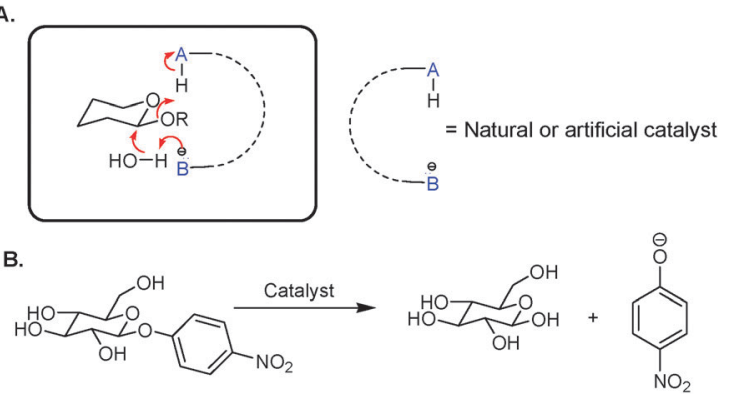

Fig. 3 (A) For the glycosidase activity the departure of the leaving group is assisted by a general-acid group; the nucleophilicity of the water molecule is enhanced by a general base moiety. (B) Catalytic hydrolysis of 4-nitrophenyl- $\beta$ D-glucopyranoside.
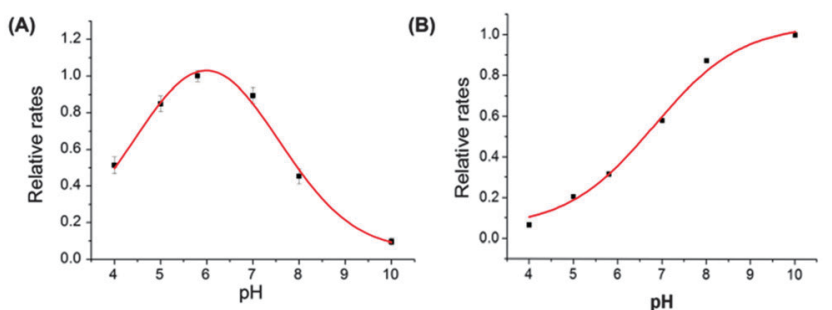

Fig. $4 \mathrm{pH}$-rate profile for the hydrolysis of 4-nitrophenyl- $\beta$-Dglucopyranoside $(1.25 \mathrm{mM})$ by $(Z)$-isomer $(\mathrm{A})$ and $(E)$-isomer $(\mathrm{B})$ at $25^{\circ} \mathrm{C}$.
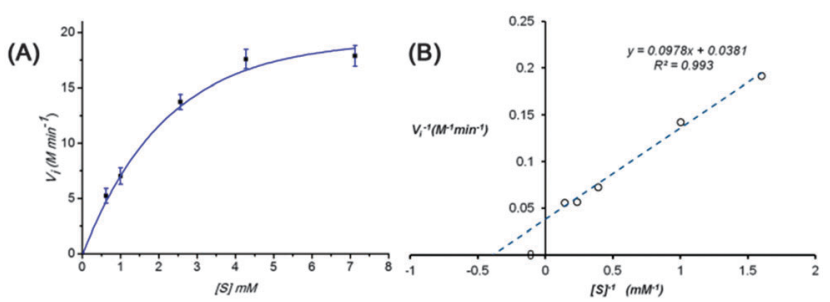

Fig. 5 (A) Dependence of the initial rate on the 4-nitrophenyl- $\beta$-Dglucopyranoside concentration for the hydrolysis reaction promoted by the $(\mathrm{Z})$-isomer $(11 \mu \mathrm{M})$ at $\mathrm{pH} 5.8$ and $25^{\circ} \mathrm{C}$. (B) The corresponding $\mathrm{L}-\mathrm{B}$ plot.

With the $(Z)$ acid the initial rates of the reaction against the varying concentrations of the substrate were plotted from the steady state kinetics data obtained at pH 5.8 (Fig. 5A). The plot displays a typical Michaelis-Menten (M-M) pattern. The rate constants $\left(k_{\text {cat }}\right)$ and $\mathbf{M}-\mathbf{M}$ constants $\left(K_{\mathrm{M}}\right)$ for the hydrolysis were obtained directly from a non-linear regression fit of the kinetic data via a double reciprocal Lineweaver-Burk (L-B) plot. The kinetic parameters obtained from the plot are listed in Table 1. It is not surprising that the $K_{\mathrm{M}}$ value of our system is higher compared to those of a number of native enzymes reported in the literature ${ }^{19}$ since this small molecule enzyme mimic does not contain a specific binding pocket.

Although the experiments were repeated multiple times, the data obtained using the $(E)$ isomer did not follow the $\mathbf{M}-\mathbf{M}$ kinetics pattern.

Molecular modeling was performed on the pyranoside substrate docked to the energy optimized (Z)-acid and explicitly solvated with water (Fig. S6, ESI $\$$ ). ${ }^{22}$ From the docked structure 
Table 1 Kinetic parameters for the $(Z)$-diacid catalyzed hydrolysis of 4-nitrophenyl- $\beta$-D-glucopyranoside at $\mathrm{pH} 5.8$ and $25^{\circ} \mathrm{C}^{b}$

\begin{tabular}{|c|c|c|c|c|}
\hline $\begin{array}{l}k_{\mathrm{cat}} \\
\left(\min ^{-1}\right)\end{array}$ & $\begin{array}{l}k_{\text {non }}{ }^{a} \\
\left(\min ^{-1}\right)\end{array}$ & $k_{\text {cat }} / k_{\text {non }}$ & $\begin{array}{l}K_{\mathrm{M}} \\
(\mathrm{mM})\end{array}$ & $\begin{array}{l}k_{\mathrm{cat}} / K_{\mathrm{M}} \\
\left(\mathrm{mM}^{-1} \min ^{-1}\right)\end{array}$ \\
\hline $2.4 \times 10^{3}$ & $4.8 \times 10^{-4}$ & $5.0 \times 10^{6}$ & 2.6 & $9.2 \times 10^{2}$ \\
\hline
\end{tabular}

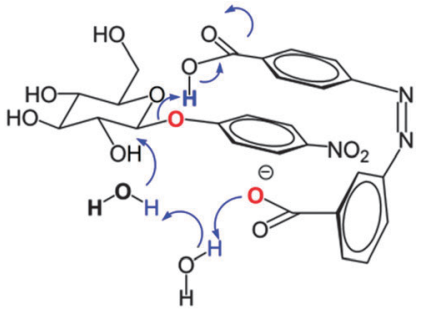

Fig. 6 Proposed catalytic mechanism of the (Z)-diacid with the substrate with 4-nitrophenyl- $\beta$-D-glucopyranoside; note the presence of the water molecule.

it was observed that two molecules of water fit between the substrate and the azobenzene molecules. It can thus be speculated that the phenolic oxygen of the 4-nitrophenyl group which is in close proximity to the carboxylic acid group of the ( $Z$ )-azobenzene is protonated by the acid (Fig. 6). The carboxylate unit deprotonates a molecule of water which in turn deprotonates the neighboring water molecule that attacks the carbon bearing the 4-nitrophenyl leaving group.

The catalytic action of the enzyme mimic can be switched reversibly with light by toggling the $(E)-(Z)$ isomerisation as shown in Fig. S7, ESI. $\$$ The thermal stability of the (Z)-form has been investigated (Fig. S8 and S9, ESI ) and the activation parameters for the thermal reaction are provided in Table S1, ESI. $\$$

The (E)-isomer of the azobenzene-3,3'-dicarboxylic acid photoswitch shows a single $\mathrm{p} K_{\mathrm{a}}$ for the deprotonation of the acidic protons, whereas the $(Z)$-isomer shows two distinct $\mathrm{p} K_{\mathrm{a}}$ values indicating a stepwise loss of the protons from the acid. In the $\mathrm{pH}$ range of 4.7 to 6.5 , the (Z)-isomer exists in the acid-conjugate base form where the $-\mathrm{COOH}$ and the $-\mathrm{COO}^{-}$groups can act as a general acid and a general base respectively. The catalytic activity of the (Z)-isomer as a glycosidase mimic at pH 5.8 was found to be highly efficient with a rate enhancement of six orders in magnitude compared to the background. This is the first example of a photo-controlled glycosidase activity with an enzyme mimic.

We thank CSIR for support (grant \# 01(2717)/13/EMR-II) and UGC, New Delhi, for a Fellowship to MS VSRK is supported by an Int. PhD fellowship from IISER Kolkata.

\section{Notes and references}

1 (a) J. Levitz, C. Pantoja, B. Gaub, H. Janovjak, A. Reiner, A. Hoagland, D. Schoppik, B. Kane, P. Stawski, A. F. Schier, D. Trauner and E. Y. Isacoff, Nat. Neurosci., 2013, 16, 507; (b) A. A. Beharry and G. A. Woolley, Chem.
Soc. Rev., 2011, 40, 4422; (c) C. Renner and L. Morder, ChemBioChem, 2006, 7, 868; (d) B. Reisinger, N. Kuzmanovic, P. Löffler, R. Merkl, B. König and R. Sterner, Angew. Chem., Int. Ed., 2014, 53, 595; (e) I. Tochitsky, A. Polosukhina, V. E. Degtyar, N. Gallerani, C. M. Smith, A. Friedman, R. N. Van Gelder, D. Trauner, D. Kaufer and R. H. Kramer, Neuron, 2014, 81, 800.

2 (a) C. Brieke, F. Rohrbach, A. Gottschalk, G. Mayer and A. Heckel, Angew. Chem., Int. Ed., 2012, 51, 8446; (b) K. Li, Y. Xiang, X. Wang, J. Li, R. Hu, A. Tong and B. Z. Tang, J. Am. Chem. Soc., 2014, 136, 1643.

3 (a) W. A. Velema, W. Szymanski and B. L. Feringa, J. Am. Chem. Soc., 2014, 136, 2178; (b) W. A. Velema, J. P. van der Berg, M. J. Hansen, W. Szymanski, A. J. M. Driessen and B. L. Feringa, Nat. Chem., 2013, $5,924$.

4 C. Renner and L. Morder, ChemBioChem, 2006, 7, 868.

5 (a) N. Muranaka, T. Hohsaka and M. Sisido, FEBS Lett., 2002, 510, 10; $(b)$ K. Nakayama, M. Endo and T. P. Majima, Chem. Commun., 2004, 2386.

6 (a) Y. Norikane and N. Tamaoki, Org. Lett., 2004, 6, 2595; (b) H. Murakami, A. Kawabuchi, K. Kotoo, M. Kunitake and N. Nakashima, J. Am. Chem. Soc., 1997, 119, 7605; (c) T. Muraoka, K. Kinbara and T. Aida, Nature, 2006, 440, 512.

7 For example: (a) Y. Oka and N. Tamaoki, Inorg. Chem., 2010, 49, 4765; (b) A. Momotake and T. Arai, Tetrahedron Lett., 2003, 44, 7277; (c) C. J. Roxburgh and P. G. Sammes, Eur. J. Org. Chem., 2006, 1050; (d) I. Takahashi, Y. Honda and S. Hirota, Angew. Chem., Int. Ed., 2009, 48, 6065 .

8 (a) Y. Wang, F. Bie and H. Jiang, Org. Lett., 2010, 12, 3630; (b) Y. Hua and A. H. Flood, J. Am. Chem. Soc., 2010, 132, 12838.

9 (a) G. H. Clever, S. Tashiro and M. Shionoya, J. Am. Chem. Soc., 2010, 132, 9973; (b) M. Liu, X. Yan, M. Hu, X. Chen, M. Zhang, B. Zheng, X. Hu, S. Shao and F. Huang, Org. Lett., 2010, 12, 2558; (c) J. Cao, J. B. Guo, P. F. Li and C. F. Chen, J. Org. Chem., 2011, 76, 1644; (d) C. Dugave and L. Demange, Chem. Rev., 2003, 103, 2475.

10 S. H. Kawai, S. L. Gilat and J.-M. Lehn, Eur. J. Org. Chem., 1999, 2359. 11 Y. Odo, K. Matsuda and M. Irie, Chem. - Eur. J., 2006, 12, 4283.

12 S. Kobatake and Y. Terakawa, Chem. Commun., 2007, 1698.

13 J. Massaad, J.-C. Micheau, C. Coudret, R. Sanchez, G. Guirado and S. Delbaere, Chem. - Eur. J., 2012, 18, 6568.

14 (a) F. Würthner and J. Rebek, J. Chem. Soc., Perkin Trans. 2, 1995, 1727; (b) M. V. Peters, R. S. Stoll, A. Kühn and S. Hecht, Angew. Chem., Int. Ed., 2008, 47, 5968; (c) D. Sud, T. B. Norsten and N. R. Branda, Angew. Chem., Int. Ed., 2005, 44, 2019For a comprehensive review on reactions controlled by photoswitchable systems see: (d) R. S. Stoll and S. Hecht, Angew. Chem., Int. Ed., 2010, 49, 5054.

15 (a) R. Breslow, Chem. Soc. Rev., 1972, 1, 553; (b) R. Breslow and S. D. Dong, Chem. Rev., 1998, 98, 1997; (c) A. J. Kirby, Angew. Chem., Int. Ed. Engl., 1994, 33, 551.

16 Artificial Enzymes, ed. R. Breslow, Wiley-VCH, Weinheim, Germany, 2005.

17 (a) D. Piszkiewicz and T. C. Bruice, J. Am. Chem. Soc., 1968, 90, 2156; (b) E. Anderson and T. H. Fife, J. Am. Chem. Soc., 1973, 95, 6437; (c) K. E. S. Dean and A. J. Kirby, J. Chem. Soc., Perkin Trans. 2, 2002, 428.

18 (a) Y. Zhou, C. M. Pedersen and M. Bols, Tetrahedron Lett., 2013, 54, 2458; (b) F. Ortega-Caballero, C. Rousseau, B. Christensen, T. E. Petersen and M. Bols, J. Am. Chem. Soc., 2005, 127, 3238; (c) J. Bjerre, E. H. Nielsen and M. Bols, Eur. J. Org. Chem., 2008, 745; (d) F. Ortega-Caballero and M. Bols, Can. J. Chem., 2006, 84, 650; (e) E. Lindbäck, Y. Zhou, C. M. Pedersen and M. Bols, Eur. J. Org. Chem., 2012, 5366.

19 (a) Q.-H. Fan, S. Striegler, R. G. Langston and J. D. Barnett, Org. Biomol. Chem., 2014, 12, 2792; (b) S. Striegler and M. G. Gichinga, Chem. Commun., 2008, 5930; (c) S. Striegler, M. G. Gichinga and M. Dittel, Org. Lett., 2008, 10, 241.

20 (a) J. McCarter and S. G. Withers, Curr. Opin. Struct. Biol., 1994, 4, 885; (b) D. L. Zechel and S. G. Withers, Acc. Chem. Res., 2000, 33, 11.

21 A. J. Kirby and F. Hollfelder, From Enzyme Models to Model Enzymes, 2009.

22 M. A. Thompson, ArgusLab 4.0, Planaria Software LLC, Seattle. 